\title{
ANENN: o esboço de um sonho ${ }^{1}$
}

\author{
ANENN: el bosquejo de un sueño \\ ANENN: the outline of a dream
}

\author{
Guilherme Nogueira de Souza ${ }^{2}$
}

\begin{abstract}
Resumo
O ano é 2004. O contexto é o intenso debate público sobre desigualdade de acesso ao ensino superior que a política de cotas para estudantes negros, adotada pela Universidade do Estado do Rio de Janeiro (UERJ), em 2002, gerou nos meios de comunicação de massa, nas universidades, nos círculos militantes e nos meios políticos institucionais. Neste contexto, um grupo de jovens universitários negros, reunidos em torno da realização do III COPENE, decide por sonhar a construção de uma organização política autônoma, composta por jovens negros, que fosse capaz de incidir sobre o debate a respeito da democratização do acesso ao ensino universitário. O presente trabalho pretende analisar o processo de construção desta organização intitulada Associação Nacional de Estudantes Negros e Negras (ANENN). A ANENN nasceu do encontro político de aproximadamente 30 jovens e rapidamente se expandiu, ampliando o escopo de participação e, também, os dilemas que envolviam a sua construção. Neste trabalho se pretende analisar os processos de negociação, articulação, construção de consensos e rupturas que o sonho de uma organização de caráter nacional impôs a esses jovens. Um dado importante a respeito da ANENN é que ela congregava militantes de vários estados da federação. Em função disto, apesar da existência de encontros presenciais, o "espaço" mais dinâmico da ANENN foi a lista de discussão na Internet. Central para articulação de jovens de diferentes estados, majoritariamente pobres e sem financiamento institucional, este "espaço" virtual foi o palco mais dinâmico para a apresentação de ideias, debates, disputas políticas e construções coletivas a respeito dos temas centrais sobre os quais a ANENN pretendia atuar politicamente. Em função desta característica, metodologicamente, este trabalho trata-se do produto de uma etnografia virtual cujo objetivo foi acompanhar as negociações em torno do esboço de um sonho.
\end{abstract}

Palavras-Chave: ação política; ANENN; etnografia virtual; juventude; movimento negro.

\section{Resumen}

El año es 2004. El contexto es el intenso debate público sobre desigualdad de acceso a la enseñanza superior que la política de cuotas para estudiantes afrodescendientes, adoptada por la Universidad del Estado de Río de Janeiro (UERJ), en 2002, generó en los medios de comunicación, en las universidades, en los círculos militantes y en los medios políticos institucionales. En este contexto, un grupo de jóvenes universitarios afrodescendientes, reunidos entorno de la realización del III COPENE, decide por soñar la construcción de una organización política autónoma, compuesta por jóvenes afrodescendientes, que fuese capaz de incidir sobre el debate acerca de la democratización del acceso a la enseñanza universitaria. El presente trabajo desea analizar el proceso de construcción de esta organización titulada Asociación Nacional de Estudiantes Negros y Negras (ANENN). La ANENN nació del encuentro político de cerca de 30 jóvenes y rápidamente se expandió, ampliando el alcance del grupo y, también, los dilemas que implicaban su construcción. En este trabajo se desea analizar los procesos de negociación, articulación, construcción de consensos y rupturas que el sueño de una organización de ámbito nacional impuso a esos jóvenes. Un dato relevante a respecto de la ANENN es que congregaba a militantes de diferentes regiones del país. En función de esto, a pesar de la existencia de encuentros presenciales, el "espacio" más dinámico de ANENN

\footnotetext{
${ }^{1}$ Artigo apresentado no Simpósio Temático 12 - Relações Étnico-Raciais na América Latina: debates interseccionais na diáspora durante o II Seminário Latino-Americano de Estudos em Cultura - SEMLACult em Foz do Iguaçu/PR, Brasil, 2018.

${ }^{2}$ Doutor em Ciências Sociais; Universidade do Estado do Rio de Janeiro - UERJ; Rio de Janeiro, Rio de Janeiro, Brasil; guilherme.souza@uerj.br guilherme.nogueira.souza@hotmail.com
} 
fue la lista de discusión en Internet. El "espacio" virtual fue el escenario más dinámico para la presentación de ideas, debates, disputas políticas y construcciones colectivas acerca de los temas centrales sobre los cuales la ANENN pretendía actuar políticamente. En función de esta característica, metodológicamente, este trabajo se trata del producto de una etnografía virtual cuyo objetivo fue acompañar las negociaciones en torno del bosquejo de un sueño.

Palabras claves: acción política; ANENN; etnografía virtual; la juventud; movimiento afrodescendiente.

\begin{abstract}
The year is 2004. The context is the intense public debate about the inequality of access to higher education that the policy of quotas for black students, adopted by the Rio de Janeiro State University (UERJ) in 2002, generated in the media of in universities, in militant circles and in institutional political circles. In this context, a group of young black university students, gathered around the III COPENE, decided to dream of constructing an autonomous political organization composed of young blacks, capable of influencing the debate about the democratization of access to University education. The present work intends to analyze the process of construction of this organization called National Association of Black and Black Students (ANENN). ANENN was born out of the political meeting of approximately 30 young people and quickly expanded, expanding the scope of participation and the dilemmas that involved its construction. In this work we intend to analyze the processes of negotiation, articulation, construction of consensuses and ruptures that the dream of an organization of national character imposed on these young people. An important fact regarding ANENN is that it brought together militants from various states of the federation. Because of this, despite the existence of face-to-face meetings, ANENN's most dynamic "space" was the Internet discussion list. Central to articulate young people from different states, mostly poor and without institutional financing, this virtual "space" was the most dynamic stage for the presentation of ideas, debates, political disputes and collective constructions regarding the central themes on which ANENN intended to act politically. Due to this characteristic, methodologically, this work deals with the product of a virtual ethnography whose objective was to accompany the negotiations around the sketch of a dream.
\end{abstract}

Keywords: political action; ANENN; virtual ethnography; youth; black movement.

\title{
1. Introdução
}

O presente trabalho é uma investigação sociológica a respeito da construção de uma organização política voltada para a demanda por políticas públicas para população negra brasileira e os dilemas políticos e identitários que marcaram o sonho de construção da Associação Nacional de Estudantes Negros e Negras - doravante ANENN. A ANENN nasceu no ano de 2004, durante a realização do Congresso de Pesquisadores Negros - COPENE -, a partir de um sonho compartilhado por estudantes universitários do Rio de Janeiro, Bahia e Distrito Federal engajados em outras organizações dos movimentos negros.

As primeiras reuniões - ainda durante a realização do COPENE - contaram com mais de trinta estudantes de diferentes universidades e destas saiu a proposta de uma organização estudantil que fosse voltada para os estudantes negros em busca de políticas de inclusão, acesso e permanência no ensino público em todos os seus níveis, com ênfase no ensino superior por meio de políticas públicas no campo educacional.

Neste trabalho não estão expostas as atuações ou atividades da ANENN, mas uma certa ênfase em suas dualidades e conflitos constitutivos. O interesse é perceber as contradições, os acordos e as oposições ao longo da formação do grupo. E, neste sentido, um dos mais amplos 
debates na constituição da organização estava assentado na pauta das identidades. Tanto sobre a identidade da própria organização, como a identidade daqueles que comporiam a organização. Nos primeiros tempos de constituição da organização, a temática da identidade foi central nas discussões coletivas, apontando para um dos muitos dilemas que se colocariam diante dos desafios de construção de uma organização.

Neste trabalho, pensamos identidades tomando por referencial a reflexão de Muniz Sodré ao nos indicar que

\begin{abstract}
A palavra vem de idem (versão latina do grego tó autò, 'o mesmo') que resulta no latim escolástico em identitas, isto é, a permanência do objeto, único e idêntico a si mesmo apesar das pressões de transformação interna e externa. Identidade - ou conformidade, por semelhança ou igualdade, entre coisas diversas - é, assim o caráter do que se diz 'um', embora seja 'dois' ou 'outro', por forma e efeito. (SODRÉ, 1999, p. 33)
\end{abstract}

A origem etimológica do termo identidade é bastante esclarecedora da forma e do conteúdo das manifestações das identidades coletivas na vida social, ou ao menos da forma que o próprio discurso identitário, e as práticas que dele decorrem, se apresentam. As identidades sociais se apresentam como realidade que emana de "iguais", a percepção da existência de "elos eternos" entre os "semelhantes" que partilham de uma essência, e como tal, atemporal. Entretanto, para além das noções nativas de identidade, o fenômeno das identidades sociais pode ser definido como "o processo de construção de significado com base em um atributo cultural, ou ainda um conjunto de atributos culturais inter-relacionados, o(s) qual(ais) prevalece(m) sobre outras fontes de significado" (CASTELLS, 1999, p. 22). Assim sendo, pode-se afirmar que, ao contrário daquilo que os próprios agentes da representação identitária apresentam como sendo um "elo eterno", as identidades sociais são construções de significado; não há na realidade social das identidades a suposta atemporalidade que existe frequentemente em sua elaboração discursiva. Assim sendo, pode-se definir as identidades como construções sociais histórico-simbólicas que se assentam sobre as relações sociais específicas no espaço e no tempo, com amplo potencial de subjetivação. Ou seja, as identidades sociais são fontes de significado construídas a partir de contextos sociais particulares e como tais, se constituem como parte de sistemas sociais de classificação e, subsequentemente, fontes de significado para a ação individual e coletiva. Desta forma, as identidades são "fontes de significado para os próprios atores, por eles originadas, e construídas por meio de um processo de individuação" (CASTELLS, 1999, p. 22) 
Também nesta perspectiva, Woodward afirma que toda "identidade é, na verdade, relacional, e a diferença é estabelecida por marcação simbólica" (WOODWARD in SILVA 2000, p. 14). O que necessariamente isto significa? Significa que as identidades são construções relacionais que elaboram o "Eu" partindo do "Outro", ou seja, as identidades possuem relação intrínseca com as diferenças sociais, sendo um fenômeno típico do contexto de inserção social objetiva marcada por disparidades. De fato, a elaboração da diferença é condição necessária para a realização do constructo chamado identidade. O discurso identitário nasce e desenvolvese em relação a um "Outro", em outras palavras, a construção identitária se dá a partir de fronteiras que delimitam a ação política e simbólica (ANDERSON, 1990).

Os elementos acionados como marcadores simbólicos da diferença são extraídos de um conjunto amplo de possibilidades culturalmente construídas. Cunha (1986) denomina estes elementos de "sinais diacríticos", diacrítico diz-se dos sinais gráficos com que se distingue a modulação das vogais; ou a pronúncia de certas palavras para evitar confusões. O conceito de "sinais diacríticos" faz referência à construção da diferença a partir de determinados elementos culturais que no contexto da elaboração identitária se propõem a marcar a "diferença fundamental" entre os grupos identitários, o "Eu" e o "Outro".

É no âmbito das identidades, especialmente no que tange ao debate sobre constituição social da organização, estratégias de composição e constituição do sentido do "ser-negro" que boa parte das discussões coletivas se assentaram nos momentos iniciais de fundação da organização. E, neste sentido, a tentativa de construção da ANENN apontava para alguns itens da pauta política que se colocava para o movimento negro no momento inicial de articulação de políticas de reconhecimento com as políticas de redistribuição, conforme a distinção apontada por Fraser (2002).

\section{Objetivos}

O interesse central deste trabalho foi analisar a construção de uma organização política e, com consequência disto, os elementos que constituíram pauta central dos debates iniciais do coletivo. E, neste sentido, os debater a respeito da representação do "ser-negro", criadas no universo dos próprios militantes no processo de construção da associação, tornou-se um tema importante que ocupou parte significativa da investigação. Assim sendo, os discursos produzidos ao longo das atividades e das questões importantes para a Associação foram o material privilegiado, no intuito de perceber as nuances das representações elaboradas pelos agentes do movimento social. Estas análises apontavam para os limites dos marcos de 
organização da pauta unificada à medida que apontavam para as contradições e disputas no âmbito da organização.

\section{Metodologia}

O presente trabalho é produto de uma etnografia virtual realizada a partir da análise do material produzido por jovens militantes no processo de constituição da ANENN. A escolha por esta metodologia em detrimento de outras se deu em função de (1) a lista de discussão na Internet ter sido o "espaço" de maior participação e turbulência na Associação, além de ser o mais acessível e plural uma vez que as reuniões presenciais foram escassas e com participação muito aquém daquela presente na lista de discussão; (2) também em função da possibilidade de alcançar, no escopo deste trabalho, vozes para além do estado do Rio de Janeiro; (3) por fim, analisar as trocas de mensagens na lista apontava para a possibilidade de acompanhar os diálogos dos agentes políticos no que tange aos temas de interesse.

Por etnografia virtual entendemos a "ação do etnógrafo em observar e classificar os fenômenos sociais, pois as diversas formas de olhar, agora em rede digital, que de antemão proporcionam o contato com um universo de possibilidades de estudos (MAUSS, 1999, pp, 0507 apud FERRAZ; ALVES, 2017, p. 5). O advento das novas tecnologias de comunicação e a incorporação crescente destes recursos à vida cotidiana apontam para o desafio de analisar os processos sociais entrecortados pela virtualização da vida e das relações, com o advento de formas particulares de troca e ação coletiva. "Conforme Mauss deixa claro, a qualidade metodológica desempenhada em qualquer campo está em reconhecer e identificar os princípios significantes do objeto estudado" (FERRAZ; ALVES, 2017, p. 6), não importando o seu perfil, se de campo ou virtual. As transformações da vida impõem também aprimoramento dos métodos de análise para construção do conhecimento sociológico.

\footnotetext{
Diferente da etnografia tradicional e suas entrevistas face a face, esta metodologia possibilita a observação do comportamento social na rede e sua interação com a comunidade online, formando um campo vasto, em que, espontaneamente, dados pessoais são tornados públicos, e, dessa maneira, é oferecida uma gama de informações para coleta de dados brutos. (FERRAZ; ALVES, 2017, p. 10)
}

Como apontam Ferraz e Alves, essa foi uma possibilidade rica de trabalho na análise da ANENN, uma vez que os agentes se referiam uns aos outros na troca de mensagens na lista de discussão, no próprio corpo do texto, o que fazia com que apresentassem um dinamismo singular para a análise. Quando a mensagem não era direcionada a uma pessoa, direcionava-se a uma postura ou posicionamento político específico. As sucessivas mensagens trocadas por 
vezes constituíram a trilha a ser seguida a respeito de um debate, o caminho a partir do qual o próprio observador pode analisar a construção discursiva, os posicionamentos diante do processo e as especificidades no interior de um movimento/ rede que estava se constituindo.

Dadas as controvérsias a respeito da cientificidade do fazer antropológico - mesmo no que se refere aos métodos tradicionais/ presenciais de pesquisa -, o presente trabalho incorpora as recomendações de Bradley (1993, p. 236) quando o autor sugere que os pesquisadores que utilizam métodos qualitativos, como o trabalho de campo virtual, busquem conferir a credibilidade da fonte e do material analisado; primem pela fidelidade na transcrição do material; e busquem posteriormente a confirmação dos dados analisados. Neste sentido, o a opção metodológica foi incorporar a integralidade das mensagens/diálogos que versassem sobre os temas de interesse na pesquisa, uma vez que a análise esteve assentada sobre os discursos produzidos no fórum virtual.

Para além da mensagem solicitando a adição ao grupo encaminhado aos administradores, não houve nenhuma outra comunicação ao grupo, além da mensagem de apresentação. Optou-se por analisar o fluxo de trocas com o menor nível de intervenção possível. No que tange à análise, a grande quantidade de e-mails redirecionados, convites para eventos mais diversos e mensagens pessoais que não possuíam relação direta com a construção do coletivo foi um dos grandes desafios da pesquisa. Dos mais de trezentos e-mails analisados para este trabalho, aproximadamente sessenta eram anúncios, convites para eventos e mensagens pessoais enviadas a algum participante da lista no Yahoo Grupos.

Quando da conclusão desta pesquisa, foram enviadas mais de mil e novecentas mensagens na lista de discussão que possui um total de mais de 270 participantes. Como todo trabalho, neste também foi feito um recorte das mensagens que seriam analisadas. A opção foi pelas mensagens enviadas para a lista ao longo de seus três primeiros meses de existência desta, entre o final de setembro e dezembro, período de maior efervescência das trocas e debates.

\section{Análise de discurso}

Durante todos os meses analisados, as seguidas mensagens tratavam a respeito do caráter da ANENN. A Associação foi organizada a partir de seguidas reuniões no Maranhão, mas nasce sem um caráter claro. Seria a ANENN uma rede de estudantes negros, ou seria uma instituição burocrática nos moldes do movimento estudantil? Seria composta apenas por negros ou não? Seria uma organização de caráter acadêmico ou militante? A ANENN seria parte integrante dos movimentos negros ou seria um movimento voltado para a pauta dos direitos 
humanos de maneira mais ampla? Ou antes, seria ANENN um movimento social? Para usar os termos utilizados por dois militantes em oposição na lista de discussão: seria a ANENN "papo de preto pra preto" ou seria uma instituição "multiculturalista"? Algumas destas questões foram respondidas ao longo do curto tempo de existência da Associação, outras ainda aguardam solução. O que se segue é um indicativo em certos casos nos quais a resposta pretensamente definitiva ainda não se encontrou. Em outros, segue-se as decisões dos militantes e a vitória de determinadas tendências sobre outras no que tange às respostas a estas questões.

Dentre as primeiras mensagens enviadas, a primeira indagação importante resume o que estava por vir: "Qual o caráter da ANENN? De jovens cientistas? De movimento estudantil negro militante? Ou as duas coisas ao mesmo tempo?” (Mensagem 12). Uma resposta possível a esta série de indagações se encontra na mensagem 13 quando um estudante do Rio de Janeiro caracteriza a ANENN, segundo suas perspectivas, como um "instrumento de luta para o povo negro sem os vícios que atormentam nossas instituições". Mesmo sendo uma definição vaga, a resposta enviada à indagação sobre o caráter da ANENN possui uma força simbólica significativa e expressa um sentimento recorrente nos discursos sobre a organização. A ANENN é pensada como uma organização grande desde o seu nascimento, mesmo que na realidade sua expressão política tenha sido pequena, o que o tempo viria a apontar logo depois. Em outra mensagem, escrita em um período de baixo fluxo de envios para a lista, uma associada escreve:

Vamos tentar não nos 'lotar' com as discussões da lista porque a construção coletiva de algo tão grande e significativo é difícil mesmo. Alinhar ideias, princípios e objetivos de Estados, pessoas e realidades distintas. Confio em todos e na construção da Associação (Mensagem 160).

Percebe-se a partir de quais perspectivas nasce a ANENN para aqueles que dela participam, algo "grande e significativo", com abrangência nacional - o que se expressa até mesmo no nome escolhido para o grupo. A ANENN nasce com a perspectiva de ser representante dos estudantes negros em busca de políticas públicas que reduzam as desigualdades sociais. Certo estudante da UFBA escreve na mensagem 7: "Temos sempre pouco tempo para retomarmos 500 anos de privações. O próximo passo é a construção". Em outro momento um estudante de Brasília afirma que

Estava faltando para o movimento estudantil brasileiro a perspectiva de homens e mulheres negros. Assim como ocorreu com o movimento feminista e o movimento homossexual já há algum tempo. Penso que, devido a experiência aqui de Brasília, o 
movimento estudantil negro tem muito a contribuir com o debate sobre ações afirmativas. (Mensagem 12)

Seguindo a trilha dos debates ocorridos por meio da lista de discussão, percebe-se a centralidade da definição da estrutura organizativa a ANENN. Havia uma preocupação constante de que a ANENN não assumisse as formas do movimento estudantil tradicional ou que não assumisse alguma estrutura excessivamente burocratizada, centralizada ou verticalizada. Havia uma clara recuso aos modelos tradicionais de organização numa perspectiva de constituição mais flexível, em formato de rede. Uma mensagem expressiva a respeito dessas preocupações foi enviada por uma estudante fluminense, em sua mensagem segue uma série de indagações que sintetizam as preocupações de muitos outros participantes da Associação. Segue a íntegra da mensagem (184):

Olá Rosana, olá a tod@s!!

Que bom que vc me respondeu, Rosana, estava começando a achar que estava clamando ao vento!!!!

Bem, creio que planos não devem ficar só no mundo dos sonhos, se queremos que a associação vingue temos que começar a analisar, discutir e definir milhões de coisas: a) Seremos uma rede de grupos negros estudantis ou uma associação institucionalizada e burocrática? Como é a UNE, por exemplo!!! São duas coisas diferentes!!!

b) Será formada por coletivos estaduais ou por grupos que já existem e que trabalham em áreas diferentes? Também são coisas diferentes, eu sou do PVNC, tenho que fazer parte necessariamente do Coletivo de estudantes negros do Rio de Janeiro para fazer parte da ANEN [Ocorreu a adição do segundo "N" após este período] ou não?

c) Como será estruturada nacionalmente?

d) Quais são os nossos objetivos e prioridades?

e) Quando vamos "aparecer" de verdade? Em que evento nacional?

Para mim deve ser no Fórum Social Mundial em janeiro, mas teremos que estar bem estruturados, lá poderemos alcançar os irmãos negr@s dos estados que ainda não fazem parte da ANEN!!

f) Vamos participar da Marcha Zumbi + 10, poderíamos estar ajudando na própria organização da marcha!!!

g) Quando faremos o nosso encontro nacional? Precisamos amadurecer o suficiente para fazê-lo, isso é fato!! Mas se continuarmos nesse estado de inércia total, nunca estaremos MADUROS!!!

h) Temos que criar outros meios de comunicação além da Internet!!

i) etc...

UFA!!!!

Ainda pensando a respeito da estrutura da ANENN e em resposta ao e-mail anteriormente citado, um estudante do ensino superior da baixada fluminense afirma na mensagem 190:

Sobre as questões colocadas, não sou simpático a uma associação institucionalizada. Aliás, seria mais coerente se a ANEN fosse uma Articulação Nacional de Estudantes Negros e não uma associação burocratizada. Isso não impede a coesão política visto 
que temos uma referência nacional, e neste âmbito é que devemos tomar as decisões. Não podemos perder a ideia da rede, pois só assim teremos um peso político para fazermos 'lobby' nas instâncias com as quais estaremos dialogando.

E continua mais abaixo afirmando qual deveria ser o espaço de atuação da ANENN, sua composição e objetivo geral:

\begin{abstract}
Sobre os objetivos e prioridades, a própria identidade da ANEN, entendo que deveríamos englobar entidades estudantis negras, movimentos de juventude negra, alunos de graduação (cotistas ou não), pós-graduação, secundaristas e estudantes de pré-vestibulares populares - estes dois últimos deveriam tornar-se atores das reivindicações, não apenas beneficiários das conquistas advindas dos esforços (um grande desafio). Tendo este perfil deveríamos estar imbuídos das ações de pressão aos setores governamentais, ao empresariado e à sociedade civil, objetivando uma maior inclusão do negro na sociedade brasileira. Isso seria um objetivo geral, mais amplo, que deveríamos esmiuçar nas ações concretas no tocante à defesa e o fortalecimento das reivindicações em torno da adoção de políticas de ação afirmativa, principalmente nas instituições de ensino superior (acesso e permanência, nas públicas de preferência) e na inserção no mercado de trabalho (já que criamos demandas de emprego).
\end{abstract}

Pelo que se percebe, para muitos militantes da Associação, o papel desta seria o depressão política junto às instâncias do Estado em busca de políticas públicas que interviessem nas dinâmicas de desigualdades sociais e étnico-raciais no Brasil. No entanto, percebe-se que, ao esboçar um projeto político de intervenção social, com uma certa pauta centrada na educação e inclusão no ensino superior, principalmente nas instituições públicas, o autor propõe que a ANENN seja um interlocutor junto ao Estado. Não há nesta construção discursiva a oposição entre Estado e movimento social, o Estado não mais é encarado como adversário, mas como instância de exercício legítimo do poder e do qual se devem retirar os benefícios almejados pelo movimento social. O Estado é um interlocutor e não um adversário. Ao menos nos meses lidos, não há essa percepção das forças públicas como adversária dos movimentos sociais. A única exceção seria no caso das forças policiais, mas ainda assim se buscam outras instâncias da máquina estatal para se debater as práticas consideradas discriminatórias e violentas pelos ativistas contra a população negra no Brasil.

Ainda tratando a respeito da organização da ANENN, certo estudante afirma a respeito da Associação que:

Entre sermos uma rede de estudantes negros ou então uma associação "burocratizada" é natural que escolha a primeira opção. No entanto, o esforço feito em São Luís era o de nos reunir visando criar um corpo político minimamente coeso, a fim de podermos intervir politicamente em determinados espaços decisórios que nos interessem atuar. Por esta razão é importante que tenhamos neste espaço de interação política e articulação tanto pessoas organizadas em grupos de estudos ou atuação política de identidade negra quanto estudantes universitários, secundaristas e pré-vestibulandos negros sem filiação a nenhum grupo. (Mensagem 188) 
A mensagem acima nos remete a uma terceira temática recorrente nas mensagens analisadas: qual seria a unidade política mínima da estrutura da ANENN, pessoas ou grupos organizados? Esta foi uma questão central no processo de organização da Associação, as definições de quem seriam os agentes nas esferas decisórias de um movimento social. Alguns possuíam um posicionamento mais agregador ao afirmar que a Associação deveria conter tanto "pessoas organizadas em grupos de estudos ou atuação política de identidade negra" quanto “estudantes universitários, secundaristas e pré-vestibulandos negros sem filiação a nenhum grupo". O que se tinha de certo em muitas falas é que a ANENN ultrapassaria o ensino de graduação e penetraria também na educação básica e na pós-graduação.

Entretanto, nem todos os filiados possuíam a mesma perspectiva a respeito da participação no grupo. Para muitos a menor unidade política da ANENN deveria ser os coletivos de estudantes negros ou "quilombos educacionais". O conteúdo da mensagem 78 é bastante elucidativo a respeito da configuração favorável a representação por grupos e não por pessoas na Associação.

A meu ver a coisa mais interessante a se fazer é (sugestão), como Lio disse na reunião, eles estão fazendo um mapeamento dos quilombos educacionais (nunca tinha ouvido este termo, achei lindo!!!) acho que esse é o primeiro passo e a partir daí tentar articular estes quilombos de forma que dali fossem tirados os representantes estaduais!!! Isso facilitaria até mesmo a obtenção de recursos para as reuniões presenciais, que devem ser feitas de forma democrática, ou seja, por todo o Brasil!!!

Esta questão da representação foi decidida em uma reunião presencial durante o Fórum Social Mundial, em 2005. Desta reunião decidiu-se que a ANENN seria composta por coletivos de estudantes negros estaduais. Caberia a estas organizações estaduais elegerem seus delegados para as reuniões presenciais nacionais. Nestas reuniões se definiriam os caminhos e os posicionamentos da Associação. Este foi o caminho mais profícuo visto que estas estruturas de coletivos estudantis negros já existiam anteriormente à organização da ANENN, seria apenas uma questão de diálogo entre estes organismos do movimento estudantil no interior de seus estados. Foi central, para opção pela segunda proposta, o debate sobre a participação exclusiva de negros ou não na Associação.

Na reunião que deu origem à rede, ficou decidido que a ANENN - como pretende o próprio nome - seria composta exclusivamente por negros. Segundo o relato contido na mensagem 47, "lá no maranhão depois de exaustiva reunião ficou-se decidido que a associação seria composta apenas por negr@s, isso é fato!! Mas, como será possível tal controle? 
Internetmente falando!!!” Esta, de fato, é uma questão pertinente. Como seria possível tal controle se a forma mais eficiente de participação na ANENN seria uma lista de discussão na Internet, aberta a qualquer pessoa que manifestasse interesse em participar? Esta questão gerou algumas contendas e foi indagada na lista pela moderadora daquele momento: "Algo a nível nacional, como é o nosso caso, que temos a Internet como maior meio de comunicação, como será possível controlar quem é negro e quem não é? Pergunto isso como moderadora!"

Em outra passagem a moderadora novamente afirma a respeito da participação de não-negros na lista e, por conseguinte, na própria Associação:

Eu não tenho como controlar isso! E acredito que ninguém tenha! Acho que a discussão não é mais se devem ter brancos ou não, a discussão é: A associação é composta por indivíduos ou por coletivos? O PréVestibular para Negros e Carentes, do qual faço parte, têm brancos, se o elo da associação for entidades, teoricamente, teremos brancos na Associação Nacional de Estudantes Negros! Os indivíduos têm autonomia, em relação aos seus coletivos, perante a associação ou não?

Várias foram as tentativas de resposta a esta pergunta. Para alguns militantes "deveria existir uma diferença entre a lista de discussão na "net" e os membros da associação de estudantes negros". Visto que seria

\begin{abstract}
Muito pertinente a preocupação com possíveis invasores não negros na lista. Neste momento é bom compreender que é imprescindível nos guiarmos pelo princípio do Protagonismo Negro na luta contra o racismo. Muitas pessoas confundem o fato de querermos fazer uma associação de alunos negros como um racismo contra brancos. O mesmo papo furado do opressor ofendido pelo levante dos oprimidos. Mas tudo bem já estamos acostumados a isso. O controle de inscrição na lista via Internet é impossível de ser feito tendo como filtro o pertencimento racial ou a militância em algum grupo de movimento social. A lista possivelmente será um espaço de agilização de informações e dos debates sobre os temas gerais que interesse a todos. Na Associação os termos são outros, se esta for institucionalizada e com sede em todos os estados. Estes filtros podem ser pensados no caso da Associação, mas na lista penso ser impossível de ser feito. (...) Não se preocupe em criar este filtro racial e militante neste momento para a lista. Ele é impossível de ser criado neste momento (Mensagem $51)$.
\end{abstract}

Entretanto, para outros militantes, “o problema racial no Brasil não é um problema dos negros, mas é um problema do Brasil. Assim todas as contribuições verdadeiras deveriam ser bem aceitas" (Mensagem 77). As contribuições verdadeiras adviriam de pesquisadores e pessoas não-negras comprometidas com a temática racial no Brasil. Porém, as questões envolvendo a participação de não-negros ultrapassavam os limites da contribuição eventual de pesquisadores, afetava diretamente a composição e as dualidades regionais do Brasil. Pelo o 
que se percebe do material da lista, vieram do Rio de Janeiro e da Bahia as maiores pressões para a exclusão de não-negros da Associação, o que feria diretamente as perspectivas dos grupos oriundos do sul do país, especialmente Santa Catarina:

\begin{abstract}
Creio que em meio a tantas discussões sobre a participação de não-negros na lista deva me posicionar. Como disse Waléria de Goiás essa questão é importante para nós do Sul do Brasil SIM, à medida que o que estamos discutindo aqui é o respeito ao trabalho de pessoas preocupadas com a promoção da igualdade racial. O que quero dizer com esta fala não é que se deva fortalecer o mito da democracia racial, mas sim que deva haver um respeito com pesquisas preocupadas com nossas lutas e anseios. Aqui no Sul temos travado uma luta árdua contra o preconceito racial e as pessoas não-negras tem contribuído e muito para o sucesso dos projetos, por isso só peço que não haja seleção para pesquisa e discussão pelo critério da pigmentação de pele, pois não podemos afirmar o que há anos estamos tentando negar e é preciso entender multiculturalismo e diversidade são bem diferentes do mito da democracia racial". Abraços e que Olorum guie nossas lutas!!! (Mensagem 116)
\end{abstract}

Entretanto este não era um posicionamento consensual na lista, na realidade este era um posicionamento pouco representativo, como se verá com as mensagens a seguir:

Vou tentar mais uma vez! Sobre o ingresso de pessoas não negras na Associação Nacional de Estudantes Negr@s: Pelo amor de Deus! Não vamos utilizar a bandeira do multiculturalismo e da diversidade para justificar nosso autoritarismo. Pelo que me consta foi vetada a presença de pessoas brancas na Associação, isso foi tirado em uma reunião que aconteceu em São Luiz durante o III COPENE, onde alunos e alunas se reuniram de forma espontânea para dar os primeiros encaminhamentos para a formação da Associação Nacional de Estudantes Neg@s. Pelo que me consta este ponto não é um ponto de pauta! Isso só será mudado em uma próxima reunião nacional e pela manifestação da maioria das pessoas participantes da lista, sinceramente eu acho que isso não vai passar quando essa reunião acontecer. É um ponto resolvido para a maioria dos militantes negr@s da atualidade, e do passado também que o lugar dos brancos aliados à luta contra o racismo NÃO É NO MOVIMENTO NEGRO!!!!!!!!!! Este pensamento é importante porque a luta contra o racismo não é um problema só dos negros mais sim de todo o Brasil e todo o Brasil não pode participar do Movimento Negro! Existem vários espaços para a luta contra o racismo se nossos amigos não negros estão realizando pesquisas que contribuem para essa luta já estão dando uma grande contribuição. Mas isso não impede de eles tomarem medidas radicalizadas. Não vejo o apoio do Movimento Estudantil Branco (UNE, DCEs, CAs etc. e tal) as ações afirmativas. Está aí um espaço para a atuação! Estão eliminando, e impedindo que muitos se formem os Grupos de Trabalho sobre Raça e Etnia da Associação Brasileira de Antropologia, da Sociedade Brasileira de Sociologia, de História, de Geografia, de Psicologia, de Letras e Literatura etc. Existem vários espaços para a atuação que não seja o Movimento Negro. (Mensagem 121)

Abaixo segue a resposta ao e-mail anterior oriunda de Santa Catarina, o primeiro afastamento da ANENN:

O racialismo pelo visto não foi superado nos movimentos dos quais vc participa. A bandeira do multiculturalismo já está em mãos negras há algum tempo e muito me espanta q vc ainda não saiba disso, não estou querendo q o movimento negro tenha 
pessoas brancas, meu querido, apenas não considero a ANEN um movimento negro, mesmo pq tem muitas pessoas na lista q vc's mesmo viram assinar na reunião do COPENE que são brancas, portanto isso contradiz o que dissestes. Então, Waldemir, PELOAMORDEDEUS, digo eu, a luta pela discriminação racial é uma luta p/ $\mathrm{q}$ a diversidade seja reconhecida, isso inclui nossa cultura, nossas manifestações, nossa história (lei 10639). É importante sabermos q grandes intelectuais do movimento negro falam em seus trabalhos da importância da integração da cultura negra às outras, a fim de ganharmos um espaço entre eles p/ que seja reconhecida a importância de nosso povo. (...) Pois p/ haver valorização é necessário lutar pela inserção nos espaços e não separar c/ uma cerquinha de arame farpado o nosso pequeno gueto. Volto a dizer que quando falei da inserção de não-negros pesquisadores na lista foi por considerar a ANEN como movimento político lutando por espaços para estudos, pesquisas, valorização, e etc, o q difere de algumas ações do movimento negro, imaginei q estivéssemos trilhando pelo caminho intelectual para dizer a importância do reconhecimento e dessa forma inserir os estudantes negros, futuros pesquisadores, doutores, no meio social, o nosso sucesso neste tipo de luta é o reconhecimento de nossa luta. Bom, já que a ANEN foge completamente ao q pensei que seria a nossa luta, boa sorte na caminhada, amigos, minha militância continua, mas não com vc's, pois enquanto vc's levam nossa população para os guetos eu vou continuar tentando mostrar aos brancos, amarelos, roxos e vermelhos a importância de nos unirmos como seres humanos. Abraços e não se esqueçam que é preciso ter autocrítica. (Mensagem 127)

O que estava em jogo neste embate era mais do que uma questão de participação burocrática, a questão era identitária. Em nenhum momento na lista engendrou-se a discussão sobre o que é "ser-negro" ou não. A coerência tácita entre os militantes e a percepção naturalizada do que fosse o "ser-negro" rompe-se exatamente no momento em que alguém nãonegro, ao menos para muitos militantes do Rio de Janeiro e Salvador, e engajado na questão racial apresenta-se como participante da ANENN. As elaborações identitárias, que são constitutivamente simplificadoras e excludentes, viram-se ameaçadas diante da permanência do "Outro" no interior de sua seara, no caso, alguém não-negro na Associação. Assim como foi feito pela militante de Santa Catarina, outros participantes não-negros retiraram-se da Associação nas semanas que seguiram aos debates acima.

Uma questão importante presente na mensagem 116 é a percepção da diferença étnica como diferença de pigmentação. Segundo a militante de Santa Catarina, não se pode utilizar o "critério da pigmentação" como base de um movimento social que, na perspectiva dela, deveria seguir os caminhos do universalismo e do multiculturalismo. Esse posicionamento diverge de muitos militantes, pois apresenta um critério diferente do critério da "ancestralidade" para a afirmação do "ser-negro". A noção de "ancestralidade" está presente no discurso de muitos militantes. "Ancestralidade” seria uma ligação mística entre as diferentes gerações de um dado povo, segundo algumas tradições cosmológicas. A "ancestralidade de luta" dos negros no Brasil atual seria herança das lutas de gerações anteriores pela "mesma causa”. "Ancestralidade” como categoria identitária possibilita uma certa continuidade no tempo, a criação de uma tradição. 
No entanto, para além do discurso da "ancestralidade" o que fica claro é que não há uma discussão clara do que seja "ser-negro", não existem critérios esboçados para tal. De igual maneira, não há critérios claros para a definição do "ser-branco" - a antítese privilegiada em toda a discussão. O critério da autodeclararão somente possui alguma funcionalidade ou validade quando ratificado por seus pares. Enquanto afirmação identitária, o pertencimento a um dado grupo ou categoria precisa ser ratificado por outros. Exatamente, por isso, fala-se em identidades sociais. Neste caso, parece que para a grande maioria dos militantes da ANENN, "ser-negro" é uma construção vocabular de autoclassificação ratificada pelos "semelhantes". Entretanto, este critério possui seus limites e estes se apresentam no momento que se coloca em questão a construção de uma pauta política por reparação e visibilidade. Será que qualquer um pode afirmar-se negro e será aceito como membro do movimento? Ou será que existem limites para os efeitos da autodeclararão? Ao que tudo indica existem limites e estes baseiam nas características fenotípicas. Para além do discurso identitário engendrado por alguns militantes baseado na ancestralidade, parece que para outros o limite do auto pertencimento são as características físicas. Neste sentido, muitos militantes dos movimentos negros não rompem com a forma tradicional de classificação quanto a origem étnica. Ou seja, as características do sistema classificatório brasileiro, assentado no "gradiente de cor", se perpetuam, fornecendo os elementos que possibilitam a classificação dos próprios militantes, mas com uma inversão dos sentidos simbólicos dos traços físicos e culturais. Há atribuição de sentidos positivos para os traços fenotípicos negroides, apesar do diálogo complexo com o sistema de classificação assentado no critério da marca, como apontou Nogueira (1954).

A definição de "ser-negro" presente neste trabalho considera a autodefinição como a única maneira de apreender as identidades sociais, apenas através da percepção do sujeito a respeito de seu lugar no mundo é que se pode construir alguma análise a respeito das identidades sociais. Partindo desta autodefinição é que todas as problematizações podem ser feitas.

A ANENN, enquanto movimento social, se enquadrava em dois universos aparentemente divorciados: o universo das "políticas de redistribuição" e o universo das "políticas de reconhecimento" (Fraser, 2000). No primeiro universo estão as demandas sociais e as reivindicações de caráter universalista, que exigem das instâncias públicas o cumprimento do princípio de isonomia política, jurídica, social e econômica. No segundo universo se encontram as dinâmicas de diferenciação e as reivindicações pelo direito à diversidade e à diferença. Estes são universos díspares, porém encontram reconciliação dentro dos movimentos sociais que possuem como pauta política ambas as formas de inclusão, o direito de ser diferente e a igualdade de tratamento diante das diferenças. Por mais antagônico que possa parecer, a 
ANENN oscilava entre estes dois universos: de um lado a busca de políticas públicas que rompessem com as dinâmicas da desigualdade sócio-racial, além do acesso às formas igualitárias de tratamento e bens sociais; de outro, o direito à diferença e a reivindicação da especificidade identitária diante de um reconhecimento inadequado. De forma simplista, poderse-ia dizer que a Associação tanto buscava a igualdade - enquanto ideal do Estado Moderno quanto a supressão das desigualdades de status. Para usar os termos de Elias e Scotson (2000), a ANENN seria um movimento de "outsiders" contra os processos de estigmatização social, tentando alterar o "carisma grupal" e o "ideal do nós".

Michel Wierviorka, citado por Azevedo (2000: 87), afirma que de "um lado, temos um paradigma universalista, moderno, cujo conceito-chave é 'humanidade'; de outro lado, temos um novo paradigma, definido por alguns como pós-moderno, o paradigma diferencialista ou comunitarista, cujo conceito-chave é a identidade racial, étnica e de gênero". Nancy Fraser (2000, p. 7) compartilha do mesmo diagnóstico ao afirmar que:

\begin{abstract}
No mundo de hoje, as reivindicações por justiça social parecem, cada vez mais, dividir-se em dois tipos. No primeiro estão as reivindicações redistributivas, mais familiares, que pretendem buscar uma distribuição mais justa de recursos e riquezas. (...) O recente ressurgimento do pensamento do mercado livre, no entanto, deixou os proponentes da redistribuição na defensiva. Ainda assim, as reivindicações redistributivas, igualitárias constituíram o paradigma para a maior parte das teorias sobre justiça social ao longo dos últimos 150 anos. (...) Atualmente, porém, e cada vez mais, vemos um segundo tipo de reivindicação por justiça social nas 'políticas de reconhecimento'. Nesses casos, em sua forma mais plausível, a meta é um mundo onde a assimilação nas normas culturais majoritárias ou dominantes não seja mais o preço que se tenha de pagar por igual respeito.
\end{abstract}

Para a autora "justiça, hoje, exige ambos: redistribuição e reconhecimento. Nenhuma delas basta por si só” (2000, p. 8). É neste ponto que se encontravam as formulações a respeito da ANENN, na busca tanto de políticas de redistribuição quanto de políticas de reconhecimento e, como argumenta Fraser, as duas tipologias de justiça social não são necessariamente excludentes.

Voltemos ao material da lista. Como argumentei anteriormente, a decisão por tornar os "quilombos educacionais" como unidades mínimas da Associação Nacional de Estudantes Negros e Negras esteve intimamente ligada à necessidade de controle dos participantes da lista de discussão, assim como a necessidade de expurgar a presença "alienígena" que pudesse gerar problemas no futuro, preocupação esboçada por um jovem estudante da Bahia (Mensagem 46). O resultado dessas preocupações foi a aceitação da proposta vinda do Rio de Janeiro para que o ingresso na lista de discussão fosse feito por indicação de algum membro do grupo, como demonstra a mensagem abaixo: 
Estou de acordo com o companheiro Ademário em limar a presença de 'alienígenas' em nosso meio. Gostaria de propor o seguinte: as pessoas poderiam participar da lista, mas segundo a indicação de outros membros, ou seja, as pessoas que já participam reivindicariam a inclusão de outro companheiro. Pois assim, teríamos o controle de quem está conosco. Evitando assim, aborrecimentos no futuro, pois só desta forma participariam contatos de confiança. (Mensagem 50)

Entretanto, como já apontado anteriormente, o que estava em jogo nas definições dos participantes do grupo de discussão era algo que ultrapassava os termos técnicos de uma organização nascente. $\mathrm{O}$ autor da mensagem 50 conclui seu raciocínio afirmando que:

A nossa organização negra está em formação embrionária, então aparecerão muitos não-negros para tentar dar a 'linha' para nós. Com discurso de 'democracia' e 'igualdade' e vários bla, bla, blas... com a tentativa de nos esvaziar. Por isso levo aos meus irmãos esta proposta, pois se no futuro for detectado a presença de não-negros na lista saberemos quem indicou a inclusão do alienígena.

Em outra mensagem (78) esta questão identitária apresentava-se sob a lógica da "coerência política" do movimento social diante dos atores com os quais o movimento pretendia se articular:

\begin{abstract}
Parem todos!!!!
Estou "sonhando", ou estou vendo falas sucessivas favoráveis à participação de brancos na associação? Onde estão as pessoas que são contrárias com os seus respectivos argumentos??? Até vc negão retirou a sua fala!!!! Eu estou começando a achar que está preste a ser quebrado o que foi votado exaustivamente na reunião!!! Falando sério, quando esta discussão estava rolando na reunião creio que de certa forma não ficaram claras algumas coisas, como não estão claras agora!!! (...) A minha opinião é, tenho amigos brancos que tem uma grande consciência racial, porém acho que de forma alguma devem fazer parte efetiva da associação. Assim como as mulheres negras fizeram um pacto com as mulheres indígenas, nada impede que brancos que são solidários a causa possam estar nos ajudando, caso seja necessário, caso contrário esta é uma Associação nacional de estudantes NEGROS, se aparecermos em uma reunião importante com um montão de brancos, por mais que sejam solidários à causa, vamos virar motivo de piada!!
\end{abstract}

Novamente a elaboração identitária vem à tona quando da afirmação feita por um estudante de Brasília a respeito da experiência como fonte das matrizes de luta da população negra. Segundo esta mensagem (80), a ANENN é uma associação nascida a partir de "estudantes que compartilham racialmente uma situação de exclusão. Branquinhos comprometidos com a desconstrução do mito da democracia racial não compartilham a nossa situação de exclusão".

Uma das mensagens mais interessantes enviadas para a lista é a que afirma ser a ANENN “conversa de preto pra preto". Esta afirmação exemplifica muito bem as fronteiras de 
cunho étnico-racial que são centrais para a organização da associação. Vendo o embate e as discordâncias a respeito do que deveria ser a ANENN, pode-se perceber também que estas dualidades e desacordos possuem também um caráter regional, como já apontado acima, especificamente, neste caso, Santa Catarina versus Bahia. Segue abaixo a mensagem

\begin{abstract}
Sugiro q, sem ofensas, @s irmão que acreditam em multiculturalismo, harmonia inter-racial, pluralidade étnica.... e toda essa milonga pseudo racial-democrática formem um grupo para discutir as práticas gerais de seu humanismo. A conversa aqui é de PRET@PRA PRET@!!! O veneno que passamos todos os dias em nossas comunidades não nos permite participar dessa suruba inter-racial. Passamos o rodo nessa discussão!??? Pois bem... espero q sim. A persistência guerreira de OGUM aponta os caminhos que temos que trilhar.
\end{abstract}

Como dito anteriormente, as identidades são "criaturas da linguagem" e são nas searas vernaculares que se engendram muitas das batalhas a respeito do "reconhecimento adequado" (FRASER, 2002) ou do adequado “ideal do Nós" (ELIAS; SCOTSON, 2000). Nesta perspectiva, o material colhido na lista apresentou uma série de excelentes exemplos de como a linguagem se altera diante das representações sociais e políticas e torna-se coerente com um projeto político-identitário que somente através dela pode tornar-se parte da realidade social; mas que, entretanto, não se limita a ela. Na mensagem supracitada, três termos chamam atenção: irmão, preto e Ogum.

O primeiro termo é interessante porque lembra a constituição de uma comunidade de iguais, o grande objetivo da fronteira identitária. A escolha do termo irmão nos remete a construção de uma representação que projeta no compartilhamento ontológico de alguma essência o elemento agregador dos indivíduos engajados nas lutas identitárias. Algo que se assemelha às formas de tratamento de muitas das facções cristãs que se tratam por irmãos e irmãs, pois creem serem filhas do mesmo Deus e Pai.

Do total de e-mails selecionados para a análise, o vernáculo "irmão" e suas variantes apareceram em diferentes momentos e no texto de diferentes agentes mais 36 vezes. Há um sentimento compartilhado, ou ao menos expresso textualmente, de uma irmandade assentada em "nossa ancestralidade", seja ela arraigada na tradição africana anterior à diáspora, seja ela assentada na tradição de luta de "nossos quilombos". De qualquer forma, o que a pretensa irmandade apresenta é a construção de uma tradição que atrela homens e mulheres que compartilham características fenotípicas semelhantes. A irmandade expressa textualmente é a construção de um discurso de tenta dar ao passado uma coerência e um fluxo continuo em relação ao presente, é o passado sendo reconstituído diante das dinâmicas e exigências do tempo atual. Neste sentido, o passado assume uma importância política, sendo menos uma narrativa 
de fatos e mais uma reconstrução interpretativa dos feitos de ontem. Os movimentos identitários reconstroem o passado em termos de suas perspectivas em relação ao presente e ao futuro almejado.

As narrativas de reconstrução do passado estão presentes em todas as elaborações identitárias, elas são parte do processo de construção da "comunidade imaginada" (ANDERSON, 1989) que se assenta sobre a "invenção das tradições" (HOBSBAWN; RANGER, 1984); assim sendo, tanto o mito da "democracia racial" quanto à irmandade assentada na tradição quilombola são reconstruções que não necessariamente coincidem com a realidade social e histórica particular dos sujeitos, mas são ferramentas de construção de um sentimento de compartilhamento histórico. Enquanto ferramentas e estratégias políticas, entretanto, há uma clara distinção de poder entre o discurso assumido pelo Estado e a tentativa de produzir um "ideal de si" adequado aos grupos subalternizados nas dinâmicas sociais brasileiras. Ainda assim, são importantes como dados da realidade por suas dimensões simbólicas e por seu potencial formador de representações e da subjetividade dos agentes sociais.

O segundo termo é "preto". Muitas já foram as expressões com as quais os ativistas dos movimentos negros se autodesignaram. Os militantes da União dos Homens de Cor se autodenominavam "homens-de-cor"; os militantes do Teatro Experimental do Negro se autodenominavam "negros"; assim como, os membros do Movimento Negro Unificado. A tendência iniciada nos anos 60 de utilizar o termo "negro" ganha corpo na contemporaneidade, assumindo nova conotação, como parte de um processo político. Independentemente das origens dos termos, o que nos interessa é perceber como as palavras são ressignificadas e revalorizadas - no sentido de assumir uma nova valoração social - diante das lutas políticas dos movimentos organizados.

Possivelmente, o termo "preto" poderia ser tomado como ofensivo ou depreciativo em outros contextos sociais. No meio dos seus, ou seja, em meio àqueles que compartilham de seus traços e suas perspectivas representacionais, o termo "preto" perde o sentido pejorativo diante de uma "gramática racial" dominante e passa por um processo de ressignificação. As lutas identitárias são também batalhas linguísticas.

Por fim, o termo "Ogum" é expressivo de uma das fontes tradicionais de conteúdo simbólico dos movimentos negros. Neste sentido, Ogum deixa de ser apenas uma entidade religiosa, dentro de uma cosmologia específica, e torna-se o elemento fonte de inspiração representacional para agentes políticos nos processos de afirmação identitária. Exatamente, por isso, é que "a persistência guerreira de OGUM aponta os caminhos que temos que trilhar". Ou 
seja, a persistência guerreira de Ogum é um símbolo da persistência necessária diante das demandas políticas que se almeja alcançar. Ademais, supõe-se que as imagens religiosas desta linhagem tenham o potencial agregador nas dinâmicas de construção das tradições e dos processos de compartilhamento simbólico das representações.

Ainda pensando a respeito das identidades sociais, creio ser interessante o posicionamento de um certo militante a respeito da justaposição do dia de celebração a Zumbi dos Palmares e o "Dia D" - campanha nacional de combate à dengue. Dentre as mensagens analisadas, esta é a única contendo uma crítica direta ao Estado e a sua atuação em relação a população negra no Brasil.

Creio que Sueli Carneiro expressou muito bem os 'atos falhos' constantes de nossa institucionalidade quando referida a datas que nos contemplam. Não há nenhum acaso nisso. Combater o mosquito da dengue é fundamental, ninguém diria o contrário. Porém, sobrepor uma campanha como está a uma data de máximo simbolismo para metade da população brasileira deixa de ser sacanagem para transformar-se em crime. Crime contra a memória que tentamos iluminar e que nos faz olhar para o passado e perceber que houveram muitas lutas contra o flagelo e opressão. Se trata de uma disputa travada no campo do imaginário; é luta simbólica contra a população negra. Enfraquecer a memória do povo negro equivale a apagar-lhe os pertencimentos, promovendo assim uma eternização da subordinação. Mesmo que oficialmente o mito da democracia racial não seja mais sustentado oficialmente, suas raízes continuam operando, na maior parte das vezes de forma oculta, em outros momentos mostrando sem pudor todas as suas garras. Temos que estar alertas. São várias frentes de batalha e esta é só mais uma delas. (Mensagem 285)

Para concluir a análise do material presente nas listas de discussão cabe citar o debate sobre a ANENN e sexualidade. Na mensagem 85 um membro da associação apresentou aquilo que tem sido a temática de muitas análises sobre os "novos movimentos sociais": a interseção entre os diferentes movimentos identitários e, por vezes, a dualidade das construções simbólicas:

Segundo a feminista Judith Butler, somos orientados socialmente a partir da heterossexualidade compulsória o que nos faz entender o mundo se pensar que existe uma economia sexual dominante modelando os nossos corpos e constituindo a nossa identidade. Quando Mott naquelas polêmicas sobre ZUMBI afirmou que este era GAY a partir de ferramentas etnológicas contestáveis e sem a mínima legitimidade (ao meu ver) sua casa foi apedrejada. Concordando ou não com ele, o fato é que sua casa não foi apedrejada por ele ter cometido erros metodológicos, mas sim porque na imagem de muitos militantes ele estava desqualificando a imagem de ZUMBI, o que significa dizer que se você é negro e gay, o seu corpo, a construção da sua identidade não podem ser considerados enquanto elementos da resistência negra, a sua suposta fraqueza o atrapalha no seu percurso de militante, pois, para isso é necessário ser forte, másculo, viril, guerreiro e etc... 
A interseção entre sexualidade e movimento negro se torna interessante por algo contido no próprio texto, ou seja, a representação heterossexual na construção do "ideal do Nós". A sobrevalorização dos padrões de comportamento heterossexuais para a construção de uma representação social do "ser-negro" no Brasil.

O sujeito da modernidade tardia (GIDDENS, 1991) ou sujeito pós-moderno na linguagem de (HALL, 1992) possui como característica as multivariadas fontes de representação identitária. As identidades fixas, organizadoras da vida, se desfizeram diante de uma realidade em constante fluxo. Assim sendo, para os movimentos sociais, há uma constante interseção entre as áreas de atuação, podendo haver relação entre os movimentos negros e os movimentos homossexuais, ou movimentos religiosos ou qualquer outro grupo organizado que possa se conectar e se vincular às especificidades dos movimentos sociais negros.

Aproveitando o mote deixado pela mensagem anterior sobre a participação de homossexuais na ANENN, uma jovem engajada nas lutas feministas e no movimento negro, além do movimento estudantil afirma:

\begin{abstract}
Como mulher, posso afirmar que desde minha inserção nos movimentos, começando pela estudantil há mais de dez anos, todo ponto tocado sobre a representação feminina era respondido assim: vc's que se organizem... o que significava dizer, em outras palavras, isso não deve ser discutido aqui e agora. Apesar da presença enfática e participativa das mulheres, o bloqueio masculino se dava desde a formação dos grupos. Com a sub-representatividade, portanto, era difícil a inserção e legitimação dos espaços do ME para mulheres e negros. Formava-se um círculo vicioso. (...) Já na formação precisamos não criar bloqueios sutis de participação; se não as/ os "evitamos" ou "proibimos" - obviamente ninguém faria isso com a/ o companheira/ o homossexual, espero - podemos, ao passar ao largo das diversidades internas e ao não pensar as representatividades nesse sentido, reproduzir o que historicamente outros segmentos do Movimento Estudantil fez com mulheres e negros, e o que historicamente fez o Movimento Negro com mulheres e com homossexuais. Assim, a questão não é querer "organizar" a luta do outro, mas ter o cuidado de não produzir um discurso homogêneo no momento em que se organiza a Associação. Ao se articular companheiras/ os, portanto, a diversidade sexual é um critério a ser utilizado. (Mensagem 93)
\end{abstract}

Ainda no trato das interseções entre os movimentos negros e as questões a respeito de sexualidade e gênero, outro militante afirma na mensagem 100:

Quanto a diversidade sexual, também não acho que heterossexuais tenham que puxar a discussão. O que eu tenho é medo profundo de tudo o que desde dos 3 anos de idade vi e acompanhei no movimento negro no que diz respeito a prática machista e homofóbica. Eu acho que estudantes homossexuais devem participar da estruturação da lista, da construção da pauta. Nós não podemos montar tudo e depois dizer: Venham! Tem um espacinho para vocês! Eu sei o que acontece nesses casos, o espacinho é realmente bem pequeno. É lógico que agora não construiremos um 
movimento político destinado a conter a homofobia, pois como você mesmo lembra, estamos estruturando a lista mas eu acho importante que estudantes homossexuais participem da concepção da lista, uma vez que seu modo de estar-no-mundo o leva a outras concepções de ser negro, homem, mulher e isto tem que estar presente.

Estes foram os temas presentes no material analisado ao longo dos três meses iniciais de organização da Associação Nacional de Estudantes Negros e Negras. Na tentativa posteriormente frustrada - de construir uma organização militante, a associação assumiu contornos de democracia representativa de inspiração liberal: a estrutura organizacional assumiu uma forma representacional, baseada na representação estadual e na eleição de delegados por Estado; as reuniões presenciais foram pensadas como momentos de decisão política da associação, enquanto a lista ainda permaneceria sendo o "espaço" mais dinâmico de troca e construção coletiva. Os coletivos de estudantes negros ou "quilombos educacionais" se tornariam a base organizacional da associação. Na prática, entretanto, como se verá abaixo, a associação, vanguardista na sua concepção, não alcançou êxito nos seus projetos de estruturação. Os espaços de debate virtual foram paulatinamente esvaziados, apesar da intensificação da circulação de informações em determinados períodos, poucas mensagens afetavam a constituição do grupo. Os encontros presenciais, dependentes de financiamento, se tornaram um desafio. E as próprias demandas e divergências dentre coletivos locais colocaram desafios intransponíveis para a consolidação deste projeto.

\section{Resultados}

A ANENN foi um movimento social cuja orientação era a busca de certas alterações na realidade social, no enfretamento do racismo e da desigualdade estrutural no acesso aos serviços educacionais e seus efeitos na reprodução geracional da pobreza e da desigualdade. Entretanto, diante das impossibilidades objetivas de efetivar uma pauta de caráter nacional, a agenda local se fortaleceu na formação de redes de estudantes negros no ambiente universitário, na formação de quadros para os outros movimentos e na busca de políticas locais de acesso e, especialmente, permanência.

Se, por um lado, do ponto de vista de suas ambições originais, a associação não passou de um sonho. Por outro lado, pode-se afirmar, que os debates na constituição da ANENN não apresentam um projeto identitário que fosse autêntico, mas expressavam os limites objetivos da constituição de movimentos de combate ao racismo em uma sociedade cujas relações raciais foram representadas como harmoniosas e cujo ideário nacional incorporou a recusa do racismo 
como expressão da nação. A composição plural da associação apontou alguns dos dilemas de constituição da pauta antirracista no Brasil. Ademais, os debates engendrados entre os militantes revelam os processos contraditórios que envolvem esta construção. Por mais que, na perspectiva de muitos militantes, a "identidade negra" seja um dado intimamente associado à existência do sujeito, atrelado a sua essência e primordial em sua vivência, a análise dos dados demonstrou o quão processual, relacional e histórico são as identidades. Os debates sobre a participação ou não de não-negros demonstraram as problemáticas da definição de fronteiras simbólicas do que significa ser negro e dos limites entre autodeclararão, por um lado, e a negociação com um sistema simbólico dominante de classificação racial assentado no preconceito de marca. Os militantes participantes da ANENN estavam em processo de mobilidade social. Exatamente por conta desse processo, por esta situação de transição, é que as questões identitárias se tornaram mais sensíveis. A ascensão social possibilitou contato com outros universos, mas também possibilitou a vivência de formas mais específicas racismo (SOUZA, 2008; 2012).

A composição social da ANENN também gerou determinadas dificuldades de acesso aos estratos originários de seus militantes. A situação dúbia gerada pela ascensão simbólica advinda com o ingresso no ensino superior público em um país no qual o acesso às universidades, especialmente às estatais, é possível a uma parcela pequena da população, gera limitações às tentativas de verter aos setores negros basais da pirâmide social os constructos identitários originados nos setores de classe média ou em ascensão. Desta forma, a associação teve uma atuação política limitada, possuindo dificuldades de acesso aos setores sociais nos quais se concentra a maioria da população negra no Brasil - o futuro da ANENN apresentava incertezas constitutivas. As elaborações identitárias, nascidas a partir da interação, por vezes, conflituosa, entre diferentes militantes, fazem referência constante à realidade social de uma pequena parcela da população negra no Brasil. O futuro chegou para a associação de modo que dois anos após a sua criação, a entidade e a lista de que lhe davam vida eram apenas um sonho cuja execução não logrou êxito.

\section{Considerações Finais}

A análise do material etnográfico apontou que a associação, enquanto movimento social, não conseguiu realizar os intentos de se consolidar como um agente político no debate sobre as desigualdades de caráter racial. Na prática, o sonho ficou apenas no seu esboço. As condições objetivas para construção de uma organização autônoma, assentada fundamentalmente em 
redes sociais, sem fontes de financiamento e sem um projeto político e administrativo claro levou o sonho a se deparar com seus próprios limites constitutivos.

Ademais, cabe frisar que a ANENN foi um sonho de jovens militantes, estudantes universitários em sua maioria, sem experiências prévias na organização de instituições. Uma organização que nasce assentada fundamentalmente em um recurso tecnológico que também era novo e cujas potencialidades políticas e organizativas ainda engatinhavam. $\mathrm{O}$ uso de redes sociais como plataforma política só vai amadurecer nos anos seguintes, demandando investimentos significativos de desenvolvedores e instituições. O avanço da tecnologia e do acesso à conexão de alta velocidade, a maior democratização do acesso aos computadores e dispositivos móveis e o surgimento de melhores ferramentas de comunicação no âmbito das redes sociais ainda era novidade em 2004. Ou mesmo em 2006, quando do final desta pesquisa. A ANENN foi um sonho para além do seu tempo. E seus quadros, jovens negros, majoritariamente de famílias pobres, sendo - em muitos casos - os primeiros a acessar o ensino superior em suas famílias, sonharam para além do que o tempo e as condições objetivas permitiam realizar. Por outro lado, o sonho da ANENN e grupos locais que lhe davam sustentação contribuiu para a formação política e de cidadania de um grupo de jovens marcados por diferentes signos da desigualdade, numa sociedade em que a realização plena da cidadania não chega às periferias das cidades - majoritariamente constituídas de pretos e pardos. A ANENN não se efetivou como instituição, mas deixou neste processo o seu legado.

\section{Referências}

ALEXANDER, Jeffrey C. Ação Coletiva, Cultura e Sociedade Civil: Secularização, atualização, inversão, revisão e deslocamento do modelo clássico dos movimentos sociais. Revista Brasileira de Ciências Sociais, jun. 1998, vol.13, no.37, pp.5-31. ANDERSON, B. Nação e Consciência Nacional, Rio de Janeiro: Ática, 1989. AZEVEDO, C.M.M. Entre o universalismo e o diferencialismo: uma reflexão sobre as políticas anti-racistas e seus paradoxos, Interseções-Revista de Estudos Interdisciplinares, ano 2, n. 1, pp 85-94, 2000.

BRADLEY, J. Methodological issues and practices in qualitative research. Library Quarterly, v. 63, n. 4, p. 431-449, 1993.

BAUMAN, Z., Comunidade: a busca por segurança no mundo atual, Rio de Janeiro: Jorge Zahar Ed., 2003.

CASTELLS, M. O Poder da Identidade. 2 eds. São Paulo: Paz e Terra, 2000.

CUNHA, M.C. Antropologia do Brasil: mito, história, etnicidade. São Paulo:

Brasiliense, 1986.

ELIAS, N.; SCOTSON, J. Os Estabelecidos e os Outsiders: sociologia das relações de poder a partir de uma pequena comunidade. Rio de Janeiro: Jorge Zahar Ed., 2000. 
FERRAZ, C.P.; ALVEZ, A.P. Da etnografia virtual à etnografia online: deslocamentos dos estudos qualitativos em rede digital. In: $41^{\circ}$ Encontro Anual ANPOCS. Caxambu, 2017.

FRASER, N. Redistribuição e Reconhecimento? Classe e Status na Sociedade

Contemporânea. Interseções - Revista de Estudos Interdisciplinares, ano 4, n.1, pp.

7-32, 2002.

GIDDENS, A. As consequências da Modernidade. São Paulo: Editora UNESP, 1991.

59

GOHN, M.G. Teoria dos Movimentos Sociais: paradigmas clássicos e contemporâneos. São Paulo: Edições Loyola, 1997.

HALL, S. A identidade cultural na pós-modernidade. Rio de Janeiro: DP\&A, 2003.

HOBSBAWN, E.; RANGER, T. A invenção das tradições. Rio de Janeiro: Paz e Terra, 1984.

NOGUEIRA, O. (1950), “A propósito de Etnias sergipanas, de Felte Bezerra” (com resposta deste). Sociologia, XII (4): 323-331, out.

. (1954), "Relações raciais entre negros e brancos em São Paulo: relações raciais no município de Itapetininga". Anhembi, XIV (41), abr.

SILVA, T.T. (org.). Identidade e diferença: a perspectiva dos estudos culturais.

Petrópolis: Vozes, 2000.

SODRÉ, Muniz. Claros e Escuros: identidade, povo e mídia no Brasil. Petrópolis: Vozes, 1999.

SOUZA, G. N. Os negros de camadas médias no Rio de Janeiro: um estudo sobre identidades sociais - Dissertação de Mestrado. UERJ, 2008.

Os negros ascendentes na região metropolitana do Rio de Janeiro: trajetórias e perspectivas. Tese de Doutorado. UERJ, 2012 